\title{
Gentrificación en Madrid: de la burbuja a la crisis ${ }^{1}$
}

\author{
Eva García Pérez²
}

\begin{abstract}
RESUMEN
En paralelo a las dinámicas de explosión urbana en Madrid durante la década 1997-2007 también los procesos de gentrificación se profundizaron en el centro de Madrid. Este artículo describe dicho fenómeno en tres barrios del centro de la ciudad: Malasaña, Chueca y Lavapiés; aportando evidencias procedentes del estudio de los cambios en la estructura demográfica principalmente, pero también comercial, e inmobiliaria. El análisis muestra que efectivamente ha habido una profunda transformación urbana en los últimos quince años, y que los procesos de gentrificación en el centro de Madrid se están consolidando, si bien con ciertas particularidades y ambivalencias. El estudio se acompaña de una reflexión sobre las nuevas tendencias ideológicas en el planeamiento urbano y las políticas públicas, que han desplegado mecanismos, tanto discursivos como jurídicos, que son coadyuvantes a los procesos de gentrificación, y que a día de hoy se apoyan en la regeneración y rehabilitación como un nuevo nicho productivo. Finalmente se toma en cuenta el contexto de crisis económica y social para lanzar nuevas hipótesis sobre el desarrollo de la gentrificación en la ciudad, entre la intensificación y la resistencia.
\end{abstract}

Palabras clave: Gentrificación, Madrid, crisis, segregación urbana, políticas públicas

\begin{abstract}
In parallel with the urban boom that occurred in Madrid during the decade from 1997-2007, gentrification increased in the downtown areas of Madrid. This article describes this phenomenon in three distinct neighborhoods in downtown Madrid: Malasaña, Chueca and Lavapiés; providing evidence from the study of changes in demographic structure, primarily, but also changes in commerce and real estate. Analysis shows that there has indeed been a profand urban transformation over the last 15 years, and that gentrification in downtown Madrid has been consolidated, albeit with certain peculiarities and ambivalences. The study is accompanied by a reflection on the new ideological trends in urban planning and public policy, which have deployed mechanisms, both discursive and legal, that are contributing to the processes of gentrification, which today rely on regeneration and rehabilitation as a new production niche. Finaly, we take into account the current economic crisis and social context, in order to propose a few hypotheses on the future of gentrification in the city, its intensification and resistance.
\end{abstract}

Key words: Gentrification, Madrid, crisis, urban segregation, public policy.

\footnotetext{
1 La elaboración de este texto se desarrolla en el marco del proyecto de investigación "CONTESTED_CITIES-contested specialities of urban neoliberalism: Dialogues between Emerging Spaces of Citizenship in Europe and Latin America" (PIRSESGA-2012-318944).
}

\footnotetext{
Artículo recibido el 15 de noviembre de 2013, aceptado el 11 de marzo de 2014 y corregido el 7 de julio de 2014.

2 Departamento de Ciencia Política y Relaciones Internacionales, Universidad Autónoma de Madrid (España).E-mail: urb.evagarciaperez@gmail.com
} 
Puede que a estas alturas el relato de ascensión y caída del ciclo económico madrileño sea de sobra conocido. Madrid ha funcionado durante la "década prodigiosa" (Burriel, 2008) del urbanismo español (1997-2007) como paradigma del modelo de acumulación neoliberal a través de la producción de suelo y vivienda y la financiarización de las economías domésticas vía créditos hipotecarios (López y Rodríguez, 2010). En este periodo Madrid pasó de figurar como poco más que una ciudad administrativa sede de las instituciones del Estado a su incorporación a los flujos de la economía global, llegándose a perfilar como centro financiero y empresarial en un régimen de competencia entre ciudades (Rodríguez, 2007). Los cambios urbanos producidos en este tiempo en la ciudad de Madrid y su región se pueden describir en torno a dos ejes: la expansión metropolitana a través de proyectos residenciales y de grandes proyectos en infraestructuras de comunicación (el parque habitacional en Madrid aumentó en medio millón de viviendas y se triplicó su precio) y las operaciones de regeneración urbana acompañadas de políticas de flexibilidad y estética sobre el espacio público (Calvo et al., 2007; García et al.; 2009).

A lo largo de estos años Madrid sufrió un empacho de grandes proyectos urbanos (cuyos retazos finales son a día de hoy los proyectos frustrados de las Olimpiadas 2020 y Eurovegas ${ }^{3}$ ) y proliferaron las operaciones urbanas en la ciudad consolidada a diferentes escalas. La mayoría de estas operaciones han estado orientadas a promover la revitalización y regeneración urbana a partir de una mejora de la escena que se identificase con la marca-MADRID. Esta recualificación medioambiental (notable en el caso de Madrid $\mathrm{RIO}^{4}$ ) ha dejado una fuerte huella en

3 Madrid ha presentado la candidatura olímpica hasta tres veces, todas de manera frustrada. Una gran parte de las instalaciones asociadas al proyecto ya habían sido construidas. El proyecto Eurovegas consiste en un gran complejo dedicado al juego de azar financiado por un magnate estadounidense que se ubicaría en la periferia metropolitana.

4 Madrid RIO es la operación que comprende el soterramiento del primer anillo de circunvalación de la ciudad a su paso por el río Manzanares. Una gran operación de infraestructura urbana sobre la que se ha construido superficialmente un parque. Su cons- el centro urbano con un número notable de intervenciones que incluye la remodelación de plazas y mercados 5 , operaciones de rehabilitación residencial ${ }^{6}$ y las nuevas líneas de actuación en relación a la producción cultural, enfatizadas por el Proyecto Madrid Centro $^{7}$ (PMC, 2011). En el conjunto de ellas se detectan formas de empresarialismo urbano (Harvey, 2007; García y Molina; 2010) que sirven, bien de mecanismo de transvase de fondos públicos al sector privado, bien como sustento de dinámicas de gentrificación donde se prioriza el carácter creativo de las intervenciones.

Por otro lado, y ahora bajo las circunstancias de la crisis, las Administraciones Públicas asumen el cambio de tendencia que ha de producirse en la economía y en el sector de la construcción a fin de poder absorber parte de los empleos perdidos, así como de impulsar otro tipo de crecimiento económico basado en los presupuestos de la sostenibilidad ambiental. Se trata de un tránsito desde la explosión territorial del boom inmobiliario al regreso a la ciudad: desde políticas urbanas que priorizaban la expansión del parque de viviendas a una recualificación del mismo. Es en esta nueva etapa urbana en la que se adivina que la ciudad consolidada y el centro urbano, en tanto que objetos de remodelación, van a cobrar un mayor protagonismo.

En esta reestructuración, que acompaña un proceso más amplio de adopción de un marco neoliberal urbano (Peck \& Ticknell, 2002) para la ciudad de Madrid (De Santiago, 2007), también se ha producido una transformación del espacio social. Los cambios demográficos y socioeconómicos producidos en Madrid se enmarcan en las mismas diná-

trucción ha supuesto un fuerte endeudamiento para el presupuesto municipal.

5 Plazas de Tirso de Molina, Callao, Sol, Plaza de la Cebada, Plaza de Sto Domingo y entorno de San Francisco El Grande; y mercados de Mercado de Barceló, Mercado de San Andrés, Mercado de Arganzuela, Mercado de San Fernando.

6 Mediante dos figuras: las Áreas de Rehabilitación Preferente (ARP) y las Áreas de Rehabilitación Integrada (ARI) previstas en el Plan General de Ordenación Urbana de 1997.

7 Documento de ideas que recoge los lineamientos para guiar el futuro de las intervenciones en el centro urbano. 
micas de transformación urbana del resto de ciudades europeas, si bien con las peculiaridades del sur geográfico, donde los cambios partían de un mayor retraso y donde la aceleración posterior ha sido más notable debido al protagonismo de los flujos migratorios, la débil intervención pública y un débil Estado de bienestar. En ellas encontramos un fuerte crecimiento de profesionales y técnicos asalariados, combinado con un fuerte cambio en los sectores más desfavorecidos, donde la industria (y con ella la clase trabajadora tradicional) deja de ser representativa y da paso a empleos de baja cualificación del sector servicios. Como conclusión se ha producido un aumento de las desigualdades en la distribución espacial de los grupos de edad, de los grupos sociales y de los grupos étnicos (Leal y Domínguez, 2008). Es en este marco de polarización urbana donde quedan englobadas las dinámicas de gentrificación.

Tanto durante el ciclo expansivo inmobiliario como en la contracción iniciada a partir del estallido de la crisis, las dinámicas urbanas han tirado del conjunto de la metrópolis madrileña produciendo dos tipos de movimientos de recomposición: de "revalorización o relegación". Mientras el centro urbano recibía el aterrizaje de la economía global y el aumento del turismo, las futuras clases medias se desplazaron a los nuevos paisajes residenciales en los suburbios, quedando los antiguos barrios obreros cada vez más deprimidos. Para Jacques Donzelot la gentrificación es una de las tres "velocidades" o vectores actuales de cambio en la ciudad, junto con la "relegación" y la "periurbanización": "en lugar de un movimiento único y unificador de los espacios urbanos asistimos al advenimiento de una ciudad de tres velocidades definida por la relegación de los polígonos residenciales y la periurbanización de las clases medias, que temen la proximidad de los excluidos mientras se sienten olvidadas por la élite de los ganadores que se dedica a invertir en el proceso de gentrificación de los centros históricos" (Donzelot, 2004). Es en este marco interpretativo que proponemos una reflexión sobre los procesos de gentrificación en Madrid, en un momento en que la crisis económico-financiera se ha traducido rápidamente en una crisis social (aumento de desempleo y la pobreza, desahucios...) que es principalmente de carácter urbano y afecta al conjunto de la metrópolis. En este mismo sentido, este trabajo supone tanto una aproximación a la gentrificación remarcándola como un fenómeno concreto de dualización social y segregación urbana, así como una contribución al estudio de la construcción del espacio social de la ciudad desde un punto de vista más amplio.

En este artículo nos proponemos explorar algunas de las variables de los cambios que transcurren actualmente en el centro de Madrid y cuyas dinámicas urbanas asociadas consideramos que implican un nuevo modelo de construcción de la ciudad. Un proyecto de ciudad cada vez más elitista donde los procesos de gentrificación van consolidándose lenta pero firmemente. Tomando como punto de partida una síntesis de los resultados de una investigación sobre las transformaciones urbanas del centro de Madrid, el objetivo concreto de este trabajo es, por un lado, brindar un marco interpretativo para comprender cómo se han gestado y desarrollado las políticas urbanas que han orientado la transformación de este espacio; y por otro, y entendido como resultado de dichas actuaciones, señalar los signos y evidencias de los procesos de gentrificación en tres barrios del centro urbano de la ciudad. En el estudio de caso se abordaron tres áreas del centro de Madrid $^{8}$ (entorno de Chueca, parte baja de Malasaña y zona de Lavapiés), donde los procesos de transformación socioespacial iniciados hace aproximadamente quince o veinte años, son hoy palpables en términos cualitativos y cuantitativos.

Metodológicamente el desarrollo del trabajo consistió en llevar a cabo una reconstrucción lo más detallada posible de la imagen de la transformación urbana a través de las variables estadísticas, intentando abarcar la multiplicidad de factores que concurren en un proceso de gentrificación. Se recurrió a las

\footnotetext{
8 La delimitación de las secciones censales escogidas para cada una de las tres zonas de estudio no corresponde con la delimitación administrativa de los barrios oficiales, que es más amplia que las zonas abarcadas y que corresponde respectivamente a: Embajadores para Lavapiés, Universidad para el barrio de Maravillas (al que nos referimos como Malasaña, Triball o entorno de la calle Pez precisando las diferentes zonas de interés), y Justicia para Chueca.
} 
secciones censales al ser la unidad territorial más pequeña de la que hay información disponible, en un periodo de estudio no menor de diez años (1998-2008) y a través de fuentes de tipo secundario. Pese a las limitaciones que pueden presentar las fuentes estadísticas, que no alcanzan a reflejar la totalidad de los cambios y en ocasiones no permiten su agregación, su análisis ofrece una lectura de las tendencias de transformación que creemos es suficientemente ilustrativa del transcurso de los procesos urbanos. La población queda caracterizada a través del Padrón Continuo en las variables de edad, sexo y origen. La variable del tiempo para establecer dinámicas de cambio ha sido muy importante, lo que queda reflejado en buena medida en el estudio de las altas y bajas de la población. Estas nos proporcionan información sobre el origen y destino de los movimientos de entrada y salida que tienen lugar en las áreas de estudio, tanto sobre la edad, el sexo, la nacionalidad, como el grado de estudios de las personas que se han desplazado. El reflejo de los cambios económicos, al no existir datos de renta disponibles, se ha intentado trazar a través de las actividades económicas (Directorio de Actividades Económicas-DUAE) que nos proporciona una idea de las pautas de consumo y cambios estructura productiva de las zonas. Los cambios en el soporte construido se estudiaron a través del Catastro, y con la información de licencias urbanísticas otorgadas, que aportaban el grado de intervención en las diferentes áreas. Por último, el análisis de precios inmobiliarios sirvió para detectar de qué manera el mercado se ha adaptado a los cambios y qué peculiaridades presenta cada zona en la estructura social del conjunto de la ciudad.

\section{Antecedentes: tendencias en el estudio de la gentrificación en España}

Para el caso de España, el estudio de la gentrificación ha debido primeramente superar la falta de literatura específica en el mundo hispanohablante a lo largo de los años noventa. Los primeros debates que a ella refieren se establecieron acerca de la definición del término y su acogida en el campo de los estudios urbanos europeos (Sargatal, 2000). Durante la primera década de los dos mil, estos debates se centraron más en caracterizar el modelo de desarrollo basado en la economía del ladrillo (Observatorio Metropolitano, 2009) y en el relato de los proyectos emprendidos en grandes operaciones urbanas (Olimpiadas de Barcelona en origen -Monclús, 2003; UTE, 2004; y el efecto Guggenheim de Bilbao posteriormente- Gómez y González; 2001), al objeto de señalar sus efectos en las desigualdades espaciales y sociales (Leal y Martínez; 2008). No ha sido hasta el final de esa década cuando el fenómeno ha cobrado relevancia en la vida académica, con el desarrollo de estudios de casos en diversas ciudades (Sevilla-Díaz, 2009; Granada-Duque, 2010) y cierta popularidad tanto en la prensa (Alpuente, 2008 y Fanjul, 2013) como en los círculos activistas (Gentrisaña y Gentripies; 2013). Su aceptación generalizada ha supuesto, además, una reapropiación del término, por cuanto se le han aportado características esenciales propias de las dinámicas urbanas de las ciudades europeas, ello sin dejar de lado un fuerte grado de politicidad que no esconde la connotación que el fenómeno conlleva en términos de lucha de clases en la ciudad (Observatorio Metropolitano, 2013).

Tal y como se discute en el artículo central de esta revista (Janoschka y Sequera, 2013), el estudio de la gentrificación en España ha puesto el foco en los siguientes fenómenos: la importancia de la inmigración internacional, el rol del Estado en la gentrificación dirigida en relación sobre todo al turismo, la gentrificación productiva o comercial, la gentrificación simbólica o relacionada con la producción cultural, las nuevas geografías de la gentrificación que la desplazan a ámbitos rurales o provinciales, y la especificidad del estudio de la resistencias a este proceso. De manera similar, para el caso de Madrid, una parte de los estudios que han abordado la gentrificación lo han hecho desde un enfoque que priorizaba el relato conjunto de las dinámicas de segregación en la ciudad tras su inserción en la ciudad global (Rodríguez, 2007), mientras otros han hecho hincapié en posibles fenómenos de elitización en el centro urbano a través del estudio de los cambios socioespaciales y demográficos (Leal y Domínguez, 2008). Sin embargo, es más bien en la actualidad cuando, a pesar de las ambivalencias y contradicciones, la gentrificación comienza a reconocerse como un fenómeno realmente existente en la ciu- 
dad, haciendo énfasis en las dinámicas del centro urbano como protagonista (Leal et al., 2012) y dentro de este, en las áreas donde los procesos de gentrificación cobran más relevancia (Janoschka \& Sequera, 2015). Sin embargo cabe señalar que la gentrificación en Madrid no queda acotada al centro de la ciudad, pudiéndose constatar evidencias de la misma en barrios de clase obrera que rodean la almendra central (tanto al norte, en el barrio de Tetuán; como al sur, en Arganzuela).

\section{Procesos de gentrificación en el centro de Madrid: Chueca, Malasaña y Lavapiés}

Unas pinceladas sobre el centro urbano pueden ayudar al lector a ubicarse mejor en el contexto local madrileño. Tanto el Centro Histórico de la ciudad, como los ensanches decimonónicos, conforman administrativamente el Distrito Centro, que se compone de seis barrios con un total de 523 ha y una población de aproximadamente 140.000 habitantes (INE, 2011). Sobre la zona rige un Área de Planeamiento Especial (APE.00.01) y de Protección Histórica (ver Figura $N^{0} 1$ ). El Centro Histórico coincide con la centralidad geográfica de la ciudad, que en su origen medieval estaba amurallada. El distrito Centro es el más denso de la ciudad (con 268 hab./ ha), a pesar de que durante cuatro décadas (1960-2000) se perdiese hasta el 40\% de su población, tendencia que se revierte a partir de 2001 gracias a la inmigración y al incremento de la natalidad (Domínguez y Vila, 2013). En ese momento el Censo 2001 seña-

Figura $\mathrm{N}^{\circ} 1$

Área central de Madrid. Distrito Centro y sus barrios. Localización de las áreas de estudio.

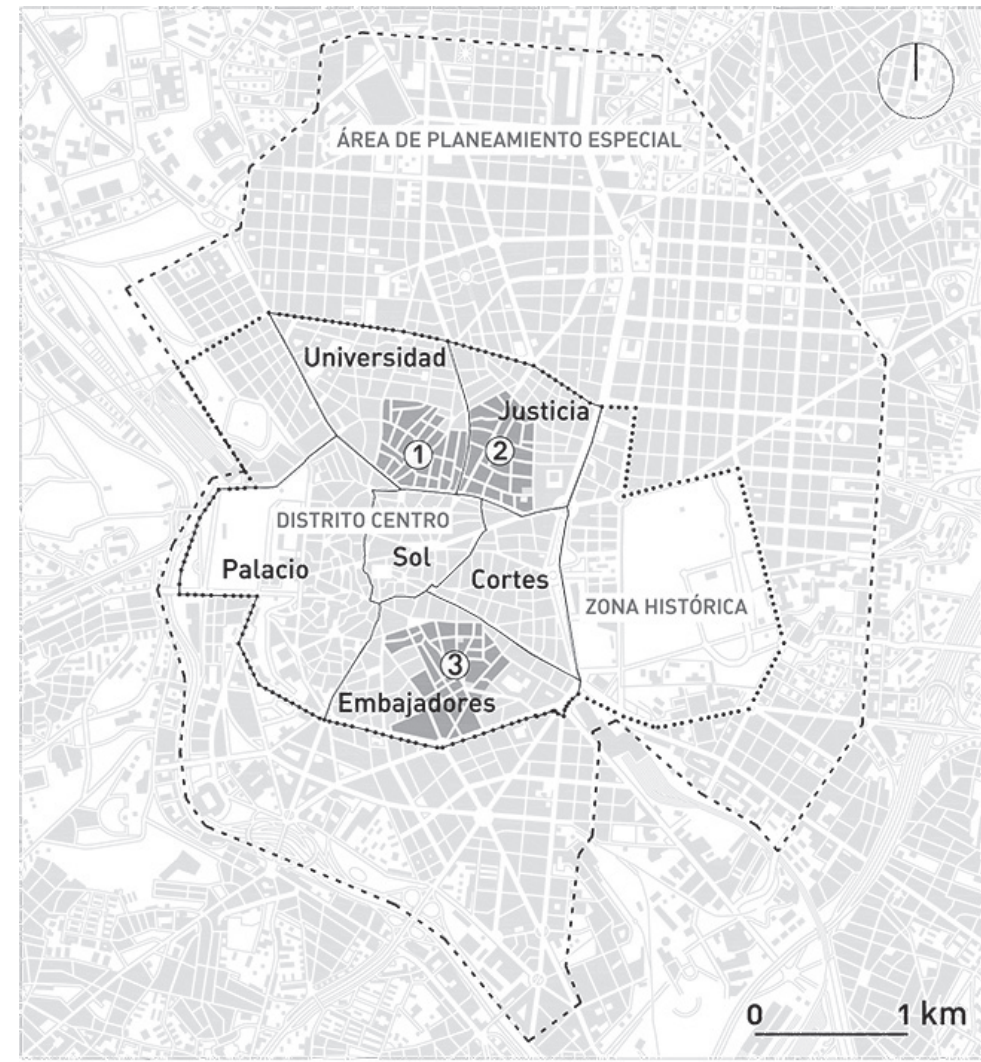

(1) zona Malasaña baja

(2) zona Chueca

(3) zona Lavapiés

Fuente: Elaboración propia en base a Ayuntamiento de Madrid. 
laba un porcentaje de infravivienda del $7 \%$ y más de un $30 \%$ de vivienda vacía. Durante todo el ciclo inmobiliario el Centro resultó favorecido, escalando sobre la geografía de precios de la ciudad hasta situarse por debajo de los distritos tradicionalmente más caros de la capital (Fernández y Roch, 2012). A día de hoy es el segundo espacio más caro en precios de alquiler, y el de mayor proporción de este régimen frente a la propiedad. Durante este tiempo, y a pesar de las inversiones en rehabilitación residencial, en el Centro Histórico de Madrid han convivido dinámicas de regeneración y degradación urbana, en una ambivalencia que lo ha mantenido como un espacio de gran heterogeneidad y complejidad social, tal y como reflejan las áreas de estudio seleccionadas.

Lavapiés tiene un rico pasado como barrio árabe y judío. Un lugar históricamente de convivencia de diversas culturas. Arrabal al sur de la ciudad, el barrio siempre ha sido destino de inmigrantes, procedentes primero de zonas rurales del país, y del extranjero a partir de los años noventa, lo que le confiere un marcado carácter multicultural. Con una alta densidad de población, la zona padece de problemas puntuales de hacinamiento e infravivienda, a través de formas de "chabolismo vertical" concentrado habitualmente en las viviendas de tipología tradicional. Estas son las "corralas", un tipo de viviendacorredor que subsiste en algunos casos con las mismas condiciones que tenía históricamente: viviendas minúsculas, con falta de servicios, ventilación, etc. Malas condiciones que se agudizan con la edad de la edificación y de la población residente.

Malasaña toma su nombre de una de las heroínas del levantamiento de los madrileños contra la invasión de las tropas napoleónicas en 1808, Manuela Malasaña. Esta imagen de resistencia se proyecta en la segunda mitad del siglo XX, cuando ve la luz un plan de reforma para toda el área - Ilamado Plan Malasaña- que pretendía abrir una gran avenida diagonal -Gran Vía Diagonal- que atravesase todo el barrio ${ }^{9}$. Este proyecto no se llevó a

\footnotetext{
9 "El Plan Malasaña, anulado por orden ministerial: Se califica al barrio conjunto históricoartístico" [en línea]. El País Hemeroteca. 28 ju-
}

cabo no solo por su alto coste económico, sino por la fuerte oposición vecinal que desató, al tiempo que Malasaña se convertía en un lugar emblemático, merced a su papel protagonista en las aperturas sociales de la Transición Política y en lugar de celebración de la "movida madrileña", que la transformaron en una muy conocida zona de ocio nocturno desde entonces hasta nuestros días.

Chueca era también un barrio de clase trabajadora, sin embargo contaba con algunos palacios en las grandes avenidas que conforman sus bordes. La construcción de la Gran Vía a principios del siglo XX segregó una parte del barrio que quedó de espaldas a la ciudad moderna, y relegada en parte del desarrollo urbano. A partir de los años setenta, Chueca comienza a conocerse como un sitio oscuro, por sus problemas de seguridad y consumo de drogas.

Nuestros casos de estudio comparten el haberse fraguado primero un carácter peculiar como lugares de ocio a partir de los estilos de vida y prácticas distintivas de diversos grupos sociales alternativos que, de manera diferenciada, se daban cita en ellas para luego convertirse en los lugares de residencia de muchos de esos jóvenes del extrarradio una vez emancipados. Así, Lavapiés ha concentrado tradicionalmente a buena parte del movimiento social de la izquierda política de Madrid. Chueca fue definiéndose lentamente como zona de ambiente (homosexual) hasta convertirse hoy día en uno de los barrios gays más conocidos y atractivos de Europa, y Malasaña fue desde los años ochenta el territorio de los más bohemios y de la música underground de la ciudad. A pesar de su relativa proximidad, cada una de ellas ha mantenido también características morfotipológicas distintivas, en lo que hace a su parque edificado y su estructura de calles y espacios públicos, así como en la distribución de las viviendas. Esto nos muestra las diferencias en el soporte edificado, entre una Chueca "más noble" y un barrio de Lavapiés con viviendas de menor tamaño y peor calidad.

nio 1977. http://elpais.com/diario/1977/06/28/ madrid/236345056_850215.html [consulta: 16 junio 2014] 
Nuestras intuiciones de partida se basaban en considerar a Chueca como un espacio donde la gentrificación está en cierta medida consolidada, toda vez que la zona ha sido ganada por la comunidad homosexual y se han transformado los usos y comercios del barrio. Considerábamos que Lavapiés presenta un proceso más complejo, de largo recorrido, donde, tanto la morfología histórica del barrio como la inmigración juegan un papel importante. Por último incluimos la zona baja de Malasaña (traseras de Gran Vía, entornos de la calle Pez y la plaza de Luna) como un nuevo territorio que es objeto de un proyecto de gentrificación inducida por parte una empresa privada Ilamada Triball10 (Janoschka \& Sequera, 2015). El consorcio busca abiertamente reproducir el canon de un proceso de gentrificación a partir de una operación de renovación comercial que sustituye antiguos prostíbulos y promueve locales de moda. La rentabilidad de la inversión, en un espacio de máxima centralidad y muy degradado, se cifraba en origen en un $30 \%$ de la revalorización del suelo.

\section{El papel de las políticas públicas en los procesos de gentrificación}

Estas transformaciones del centro urbano han transcurrido apoyándose en la orientación de las políticas de planeamiento previstas para el centro de la ciudad, entendidas estas como un conjunto de medidas normativas, legislativas y jurídicas, que han servido, aunque sea de manera contradictoria, de soporte para los procesos de gentrificación. Se

\footnotetext{
10 TriBall (Triángulo Ballesta: http://www.triballmadrid. com), es el nombre comercial de un conglomerado de empresas especializadas en la rehabilitación y gestión inmobiliaria que desembarcó en 2008 en la zona en torno a las calles Ballesta, Desengaño y Barco. Así ha quedado rebautizada comercialmente -y en ocasiones institucionalmente- la zona baja de Malasaña. Con la construcción de la Gran Vía a partir de 1910, el caserío tradicional del centro de Madrid quedó dividido en dos, dejando a esta zona detrás de los nuevos rascacielos. Especialmente desde la posguerra, esta zona se impregnó de una marginalidad creciente y ejerció como barrio de prostitución en las "traseras" de la avenida principal de la ciudad.
}

pueden comprender en torno a tres grandes etapas que referimos a continuación.

En un primer momento el centro de Madrid no es ajeno al relato de degradación que sufrieron la mayor parte de ciudades en el último tercio del siglo XX, en el que las dificultades de adaptación a los cambios sociales y económicos venían de la obsolescencia funcional de una realidad rígida físicamente, cuya adaptación a los cambios exigidos por las nuevas actividades económicas y la necesidad de nuevos servicios se hacía muy difícil. Los cambios que se produjeron a partir de los años ochenta, se tradujeron en procesos de terciarización masiva, deterioro de la edificación, infrautilización de espacio residencial y degradación social. Es en este contexto en el que surgen las primeras políticas de recuperación de los centros degradados basadas en la protección del patrimonio: proyectos URBAN, Áreas de Rehabilitación Preferente, y Plan General de 1985, cuyo eslogan era "Recuperar Madrid". El enfoque de dichas actuaciones partía de postulados que defendían la conservación urbana con un marcado carácter historicista, para posteriormente evolucionar hacia la preservación de las mismas como áreas visitables o temáticas a lo largo de la década de los noventa (Troitiño, 1992).

Una segunda etapa, que se extiende a toda la década de los años noventa, se inicia con la reorientación de los nuevos modelos de gobernanza, entendidos estos como un nuevo estilo de gobierno urbano en el que destaca la negociación y un mayor grado de cooperación entre actores públicos y privados organizados en redes de carácter mixto, donde la economía y la gestión cobran protagonismo (Cerrillo i Martínez, 2005). En esta etapa varía la consideración de los centros, ahora considerados como áreas vivas que pueden ser al tiempo exponente de la identidad o esencia de una ciudad acompañándose de políticas de adecuación, cambio de imagen y promoción de marca de ciudad. Quizás el exponente más reconocible internacionalmente a este respecto sea Barcelona. La ciudad catalana fue, desde las Olimpiadas del año 1992, la que mejor supo implantar este nuevo modelo urbano y crear una identidad propia, tanto en la manera de hacer urbanismo como en la generación de una imagen 
contemporánea y reconocible al exterior (Borja, 2009; Delgado, 2007). Durante la primera década de los dos mil, Madrid intentará encontrar su propio camino basándose en su inserción como metrópolis global, tanto a través de la creación de diferentes organismos dependientes del propio Ayuntamiento como a través de instrumentos de planeamiento blandos o complementarios al Plan General, que ya sea en forma de planes directores, planes estratégicos o planes especiales, buscan nuevas ideas de intervención ${ }^{11}$ a partir de premisas hasta ahora insólitas para lograr "estrenar un nuevo Madrid" (Proyecto Madrid Centro-PMC, 2010).

A partir de aquí comenzaría una tercera etapa, que comprende la adaptación de las políticas públicas urbanas a la fórmula del "planeamiento estratégico", un método para dar cabida a un "urbanismo flexible" que se adapte fácilmente a las necesidades cambiantes de las metrópolis modernas. Para justificar el marco de las actuaciones dentro de unas líneas estratégicas de preferencia, la política urbana adopta la forma y modos de una empresa de comunicación y promoción, donde el producto inédito que se promociona es la propia ciudad. El centro urbano adquiere aquí un protagonismo relevante, puesto que además de sus valores de centralidad geográfica se convierte en el espacio simbólico de representación de todo un modelo de ciudad, un escaparate en el que reflejarse. Para ello, y con la ayuda del marketing urbano, el turismo, la cultura y el medio ambiente vienen a componer la tríada en la que estos planes buscan su legitimidad (García, 2012).

Cultura, turismo y medio ambiente como vectores de la transformación física y económica

Para el caso del centro urbano estas premisas de planeamiento se han declinado en

\footnotetext{
${ }^{11}$ Se crearon entre otras la Oficina Madrid Global, el Observatorio Económico, y el Observatorio de las Migraciones, pero buena parte de ellos no existen a día de hoy. Por otro lado se aprobaron diversos planes: Plan Estratégico de Rehabilitación del Centro Urbano, Plan de Paisaje, Plan Especial Recoletos Prado, etc.
}

proyectos de recualificación y regeneración que tienden a poner en valor el espacio urbano a través de dos mecanismos: por un lado, su inserción y relación dentro con un conjunto de actividades económicas englobadas en la economía cultural y de servicios. Por otro, la intervención sobre el espacio público para lograr una mejora del medio ambiente urbano.

Para el primero de ellos, el vector de la cultura opera como un argumento irrebatible (por cuanto la cultura es benevolente y no dañina). La museificación y la saturación cultural de barrios como Lavapiés a partir del desembarco de instituciones culturales público-privadas, es probablemente uno de sus efectos más visibles. Promover la ampliación de la oferta cultural, o el despliegue de contenedores museísticos, son, desde la óptica de la producción, los elementos conectores que permiten la articulación de estrategias de generación de marca urbana o de operaciones de renovación que acaban teniendo un efecto sobre el valor del suelo y en la captación de inversión exterior, vía el aporte del turismo o de las empresas multinacionales. Este tipo de intencionalidades sigue la estela de lo promulgado por el autor del concepto de "clase creativa", Richard Florida (2009), y conlleva a que las instancias públicas actúen como promotores urbanos, alentando la inversión privada selectiva para alcanzar más eficazmente aquellos objetivos de regeneración urbana capaces de "atraer el talento" a la ciudad (García, 2012). De esta forma el argumento de "más cultura" es virtuoso por: es un instrumento que se pretende presentar como generador de valores democráticos y de convivencia (PCM, 2011), al tiempo que un factor de desarrollo económico y un aliado del turismo. Este último supone una vía importante de ingresos a la economía de las ciudades centrales, y tras el espejismo financiero del Madrid global la ciudad se ve decidida a apostar por los servicios como motor económico, para lo cual es necesario "lograr una imagen urbana identificable" que pueda ser convertida en atractivo turístico, tal y como se expone en el PCM-2011.

Junto con la cultura y el turismo, la degradación del centro urbano es combatida también mediante la actuación sobre el 
medio ambiente urbano. Es necesario un medio ambiente más saludable para que las ciudades sean lugares 'donde vivir con mayor calidad de vida'. En ese sentido "se consideraba prioritario adoptar medidas que hagan más atractiva la vida en el Centro, tanto para mantener la población actual, como para atraer a nuevos pobladores" (PERCU- pág. 52). En este propósito, a pesar de lo loable de su argumento, la excusa de la calidad ambiental deviene en coartada para la puesta en práctica de proyectos de tipo higienista. Esta aparece como mero escenario verde para acciones cuyos objetivos están lejos de instaurar verdaderas medidas correctoras que potencien el desarrollo ecológico de la ciudad, sino tan solo la transformación superficial del entorno: "el espacio público en sus diversas opciones de plazas, calles, o patios... es una gran oportunidad urbana. Intervenir en él es la mejor posibilidad para estudiar operaciones posteriores, que tendrán así una mayor articulación, penetración y posibilidad de repercusión en una mayor ámbito" (PERCU, p. 111).

En nuestras tres zonas de estudio, la iniciativa de la Administración y el acompañamiento en el proceso de revitalización del centro urbano han consistido al menos en dos tipos de actuaciones: la rehabilitación edificatoria a través de programas específicos; y la modificación del espacio público. La primera se vehiculizó a través de las Áreas de Rehabilitación Integrada -ARIscon tres fases operacionales en Lavapiés, una en el eje de la calle Hortaleza (Chueca) y otro en el área Pez-Luna. La segunda, el efecto de la transformación de la escena urbana, es un factor fácilmente identificable en estos ámbitos. La rehabilitación de equipamientos singulares y la remodelación de todas las plazas de Lavapiés (Ministriles, Cabestreros, Agustín Lara, y Lavapiés) se ha hecho sentir en los últimos ocho años. Además, la reciente peatonalización de la calle Fuencarral, convertida en un eje comercial a cielo abierto, y la modificación de los viales así como la intervención sobre la plaza de Luna para adaptarla al emplazamiento de eventos comerciales y publicitarios, han transformado notablemente los usos de las calles traseras de la Gran Vía, por las que empieza a desplazarse el fenómeno de las franquicias de moda. Todas estas son opera- ciones comunes en un proceso de mercantilización de la ciudad que empieza a extraer rentabilidad del proceso de transformación del centro urbano.

\section{Consecuencias sociales de las transformaciones urbanas en el centro de Madrid}

Si hacemos un acercamiento al Distrito Centro a través del estudio de la condición socioeconómica (Muñoz, 2009) se revela que, entrando en la década pasada, el centro de Madrid comenzaba a dar signos de revitalización: se produjo un aumento generalizado de las variables socioeconómicas, con particular incidencia en el centro (donde sin embargo persistían focos con valores más bajos que la media, como Lavapiés). Al mismo tiempo que progresaba el nivel educativo y mejoraba la media salarial, disminuía notablemente el tamaño del hogar. Todo el centro en su conjunto ha experimentado un aumento de la densidad de población y su rejuvenecimiento, sobre todo en los cohortes comprendidas entre los 25 y los 45 años (Figura $\mathrm{N}^{\circ} 2$ ). El comportamiento del mercado inmobiliario del distrito Centro lo alzó hasta posiciones ventajosas y produjo una revalorización económica generalizada del conjunto (Figura $\mathrm{N}^{\circ} 3$ ). Todas ellas son variables a pesar de las cuales el centro continúa siendo un lugar heterogéneo y complejo que alberga simultáneamente dinámicas de regeneración y decadencia.

Nuestras tres zonas de estudio forman parte de esas dinámicas aparentemente contradictorias: ¿qué evidencias encontramos para la existencia de procesos de gentrificación?, ¿cuáles son sus principales características?

El análisis de los movimientos del Padrón de Habitantes (entradas y salidas), revela, por el volumen de los movimientos metropolitanos y la procedencia de los desplazamientos, una pauta de regreso desde la periferia municipal y nos lleva a pensar en un cambio en las dinámicas de elección residencial, que mostrarían un interés renovado por estos espacios (Figura $\mathrm{N}^{0}$ 5). Tanto jóvenes nacionales, hijos de los hogares que anteriormente se instalaron en las coronas metropolitanas, 
Figura $\mathrm{N}^{\circ} 2$

Pirámide de población Distrito Centro. Elaboración propia.

edad

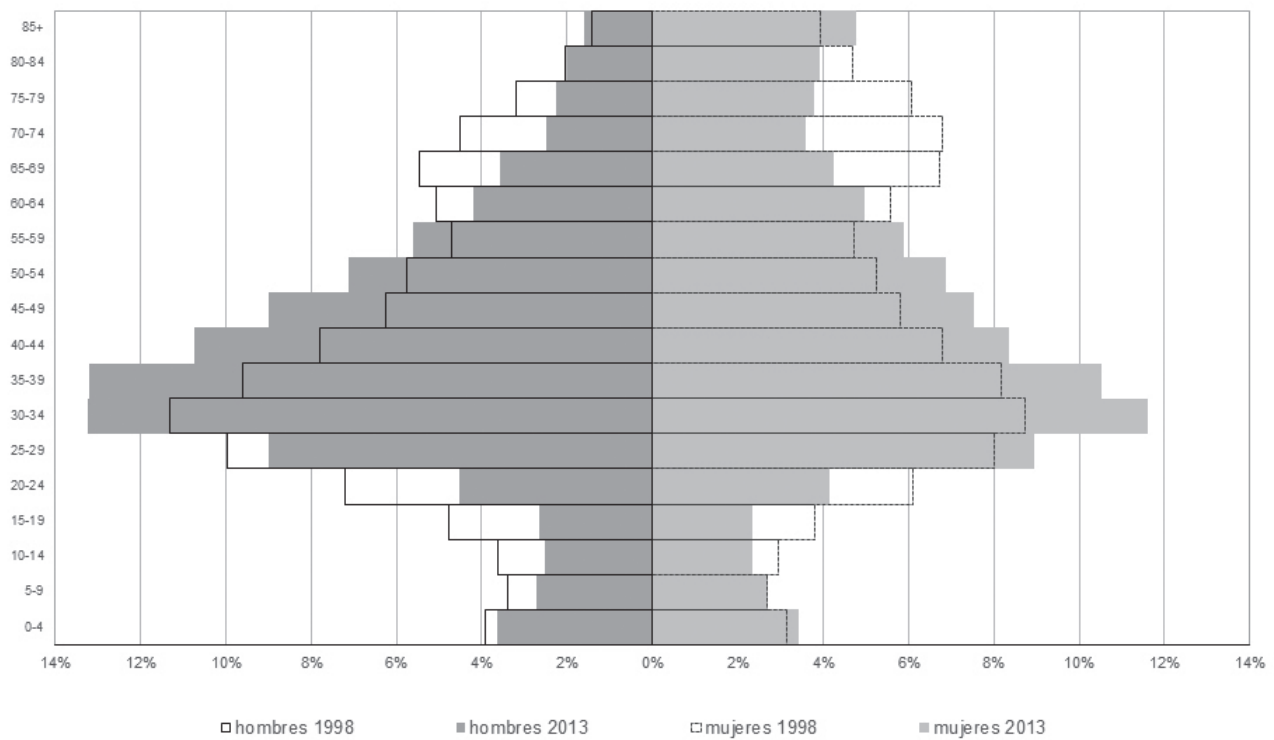

Fuente: Elaboración propia en base a Padrón Continuo, INE.

Figura $\mathrm{N}^{\circ} 3$

Evolución del precio de la vivienda de segunda mano por barrio [€/m²]. Elaboración propia.

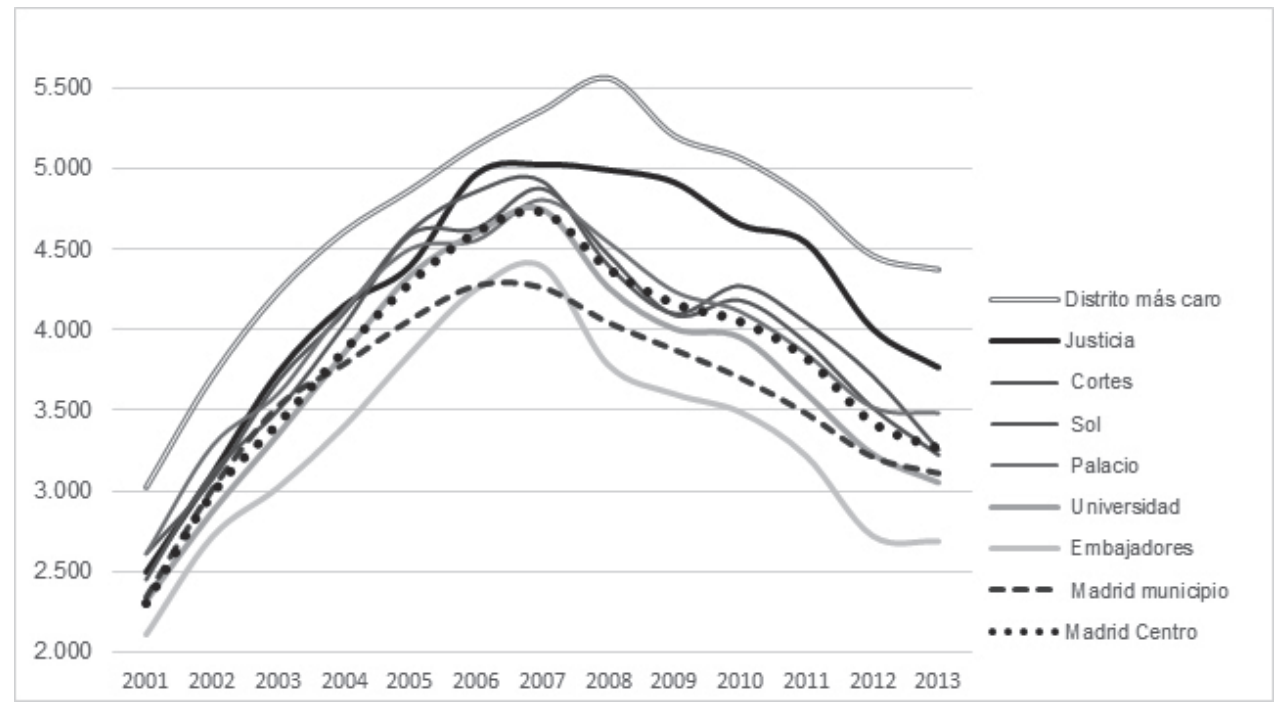

Fuente: Elaboración propia en base a Idealista.com-Índice Inmobiliario Anual 
como inmigrantes en busca de una oportunidad de mejora de sus condiciones de vida, estarían detrás de la disminución de la edad media de la población en nuestros ámbitos de estudio (Figura $N^{\circ} 4$ ).

Figura $\mathrm{N}^{\circ} 4$

Evolución de la edad media. Elaboración propia.

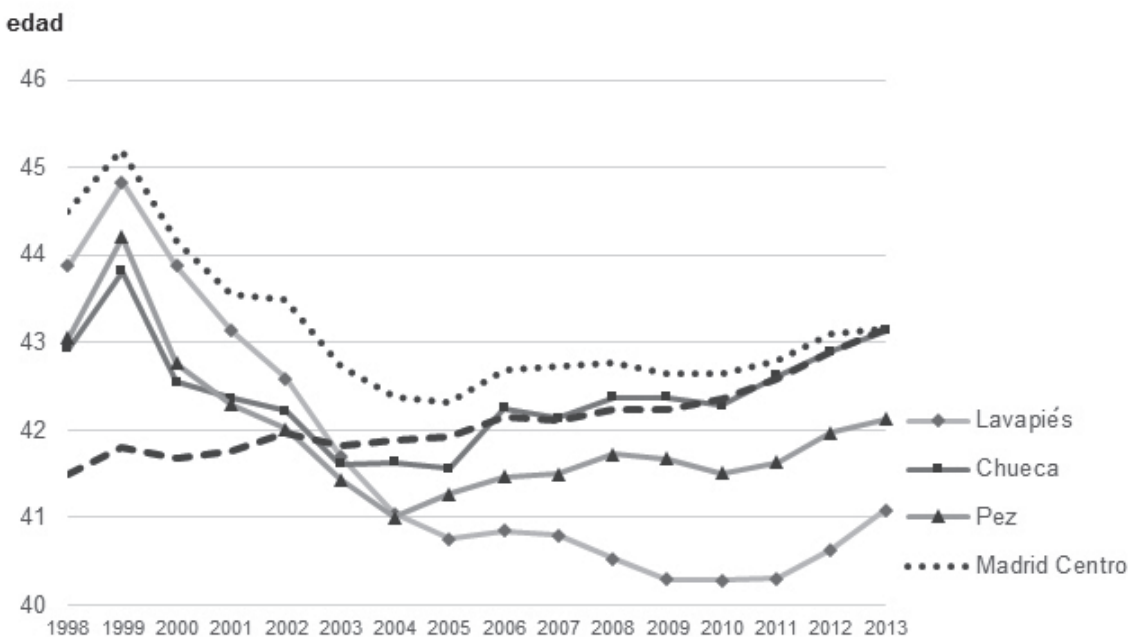

Fuente: Elaboración propia en base a Padrón Municipal. Instituto de Estadística de la Com. de Madrid.

Figura $\mathrm{N}^{\circ} 5$

Lavapiés: balance de altas y bajas en los cambios de domicilio y residencia. Elaboración propia.

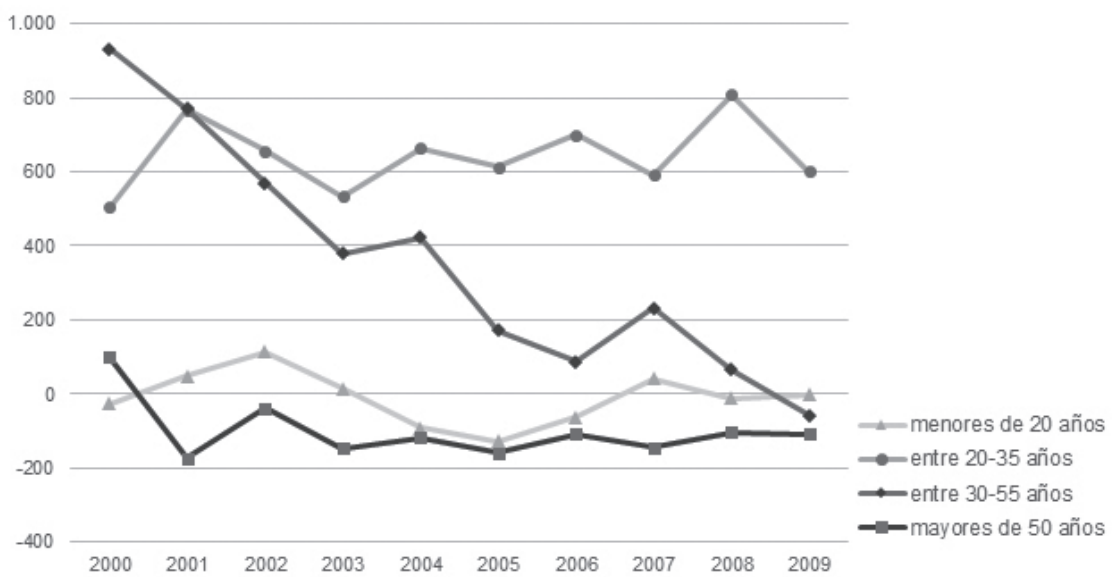

Fuente: Elaboración propia en base a Altas y Bajas del Padrón Continuo. DG Estadística Ayto. Madrid. 
La alta movilidad se perfila como una característica esencial del conjunto de la población del centro urbano. La contabilidad de flujos de los movimientos reflejados en el Padrón nos indica que esta población no permanece ni se arraiga en un determinado lugar, alterando en buena medida los modelos clásicos de convivencia habitacional por otros modelos más efímeros. Ambos colectivos, jóvenes y migrantes, comparten un mismo patrón de ubicación residencial basado en el mercado de alquiler, así como una gran movilidad, ya que la primera elección de residencia no es la definitiva, no primando el acceso a los servicios o la calidad del medio ambiente. Aún siendo esto así, esta población se distribuye de acuerdo a la oferta diferenciada de los productos inmobiliarios, provocando diferentes formas de concentración dentro de la zona Centro (Figura No 3 ).
Bajo ese efecto, la población extranjera (Figura $N^{\circ} 6$ ) tampoco se distribuye por igual a lo largo del centro de la ciudad: en 1998 la inmigración en el Centro estaba en torno al $10 \%$. Diez años más tarde todos los valores aumentan, y en Lavapiés los extranjeros alcanzan casi el $40 \%$. Además de esta tendencia, que acentúa las diferencias entre las distintas áreas del centro de Madrid, el reparto de la población extranjera es muy diferente según su origen. La población procedente de Europa (EU-15) y América del Norte (Estados Unidos y México) está mucho más presente en Pez y Chueca, mientras que para la población procedente del resto de países la situación es inversa, los valores superiores se concentran en Lavapiés. El efecto de la crisis se refleja en la caída de población extranjera que desciende bruscamente en los últimos dos años.

Figura $\mathrm{N}^{\circ} 6$

Evolución de la población de nacionalidad extranjera. Elaboración propia.

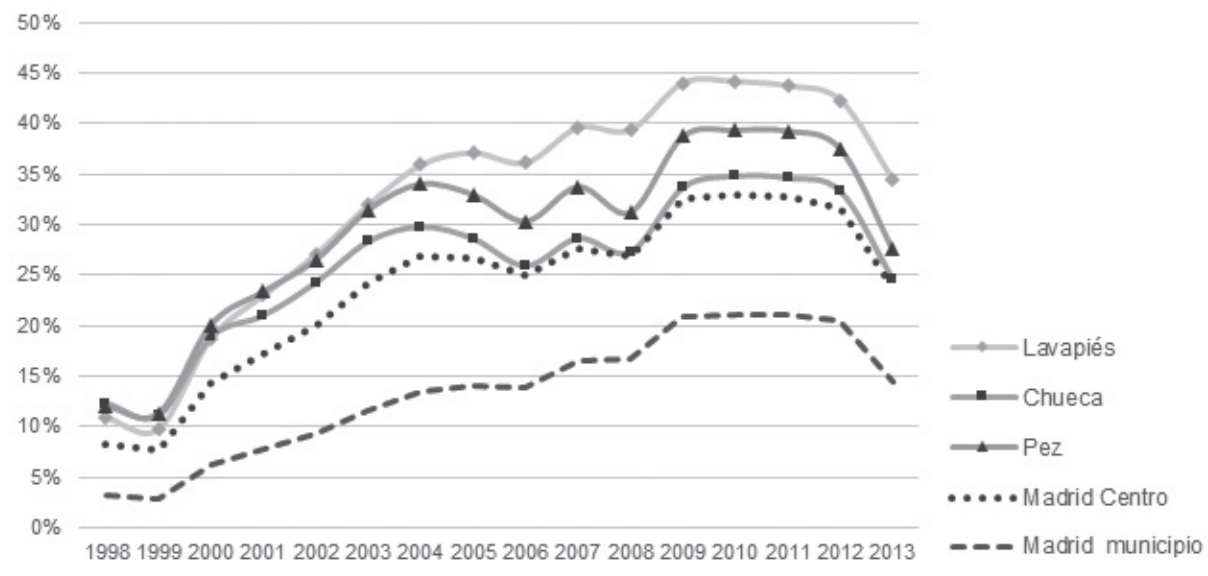

Fuente: Elaboración propia en base a Altas y Bajas del Padrón Continuo. DG Estadística Ayto. Madrid.

Del análisis demográfico se extrae que la estructura de población está cambiando en el centro de Madrid en varios aspectos. El habitual problema de la población envejecida ha dejado paso a dos tendencias. Por una parte a un numeroso colectivo de treintañeros que se hace aún más presente en nuestras zonas de estudio, demostrando así cómo ciertos entornos céntricos se convierten en lugar de residencia preferente de un cada vez más numeroso grupo de universitarios (Figura $\mathrm{N}^{\circ}$ 7). Por otro lado, algunas áreas del centro se convierten en espacios receptores de la inmigración trasnacional (Figura $\mathrm{N}^{\circ} 6$ ). Esta renovación de la población original está produciendo, además de un rejuvenecimiento de la misma (Figura $N^{\circ} 4$ ), una redensificación de los tejidos antiguos que vendría a compensar el tradicional abandono que sufrieron años atrás las áreas centrales. Las tres áreas cuen- 
Figura $\mathrm{N}^{\circ} 7$

Chueca: balance de altas y bajas de población según nivel educativo. Elaboración propia.

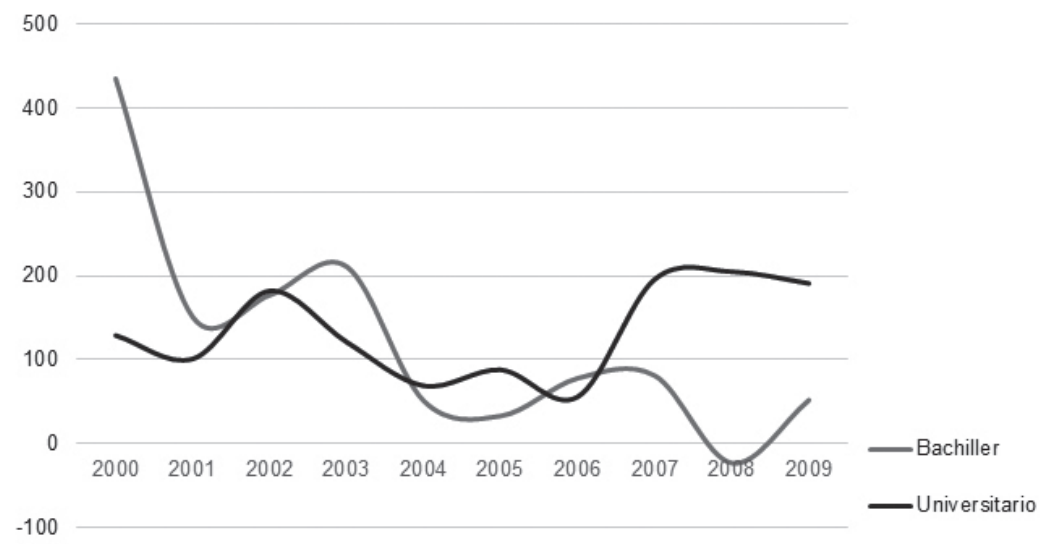

Fuente: Elaboración propia en base a Altas y Bajas del Padrón Continuo. DG Estadística Ayto. Madrid.

tan con densidades de población por encima de la media de la ciudad y reciben población por encima de la media del conjunto.

Consecuentemente, al tiempo que cambia la población lo hace la escena urbana, que refleja un mayor peso de la hostelería y de las actividades recreativas así como una especialización comercial basada en la moda, restando riqueza al conjunto de las actividades y ocasionando la pérdida del comercio tradicional y de proximidad. Si bien el distrito Centro ha sido tradicionalmente un lugar de alta concentración de actividades económicas fruto de la centralidad y accesibilidad, en los últimos años ha experimentado una disminución de su peso relativo dentro de la economía metropolitana al tiempo que una recualificación de sus actividades.

Según datos del Directorio de Actividades Económicas, entre 1998 y 2008, Lavapiés sufre un incremento de la actividad comercial (del 55\% al 63\%) que duplica la media del centro $(35 \%)$, probablemente por la intensificación del comercio mayorista en la zona. Chueca sobresale por un aumento de la hostelería en cinco puntos por encima de la media del distrito Centro $(24 \%$ frente a 19\%). Mientras la estructura económica del entorno de la calle Pez Ilama la atención por el aumento en cuatro puntos de las actividades empresariales e inmobiliarias en esta área, que entendemos puede ser debido por su relación con la Gran Vía y por la presencia de promotores inmobiliarios como Triball. Detectamos cómo uno de los rasgos de diferenciación es el hecho de que las actividades asociativas y recreativas, que incluyen también las actividades deportivas y los servicios personales, estén muy por encima de la media del centro y experimenten aumentos significativos. El cambio comercial es también muy visible a nivel del paisaje urbano. Un observador atento detectaría que en los últimos cinco años en la calle Pez se han renovado más del $30 \%$ de los comercios, mientras apenas un $15 \%$ son comercios antiguos y casi un $20 \%$ de los locales han cerrado.

\section{Un nuevo marco para la regeneración urbana}

Lo expuesto hasta aquí nos ha permitido comprender cómo Madrid se ha adaptado al proyecto de ciudad neoliberal desde el comienzo del pasado ciclo económico, así como mostrar los elementos suficientes para poder afirmar que los procesos de gentrificación se producen, en cierto modo, acompañados y auspiciados por las políticas urbanas y la intervención estatal. A día de hoy, como resultado de los excesos de la década anterior, emerge sobre el anterior un nuevo discurso institucional que pretende impulsar un cambio de modelo productivo, auspiciando 
la "vuelta a la ciudad" desde principios de sostenibilidad ambiental Lejos aún de un crecimiento realmente verde, las políticas estatales y municipales prefieren reorientarse hacia el mercado de alquiler, la construcción de vivienda protegida y la rehabilitación, donde la intervención sobre el patrimonio construido vuelve a cobrar relevancia. Estos presupuestos de "retour en ville" (Bidou y Zachariasen, 2003) entrañan, no obstante, ciertos riesgos, sobre todo si tenemos en cuenta que, como resultado del ciclo anterior, toda el área central de la ciudad empieza a resentirse de procesos de gentrificación cada vez más consolidados. Las medidas anticíclicas adoptadas, y las que están por llegar, anticipan una posible cuarta etapa que redunda en los intentos de desregulación en la intervención del centro urbano para reactivar un posible nicho inmobiliario, y que pueden suponer una mayor violencia en el desalojo de la población residente con menos recursos. A continuación referimos los aspectos en los que merece ser precavido ante las nuevas medidas adoptadas, y sus posibles efectos sobre las dinámicas de gentrificación, tanto en la creación de nuevas fronteras como en la intensificación de los procesos ya exitosos. Cuatro son las claves a tener en cuenta: alquiler, rehabilitación, protección patrimonial y seguridad.

1) Como resultado de la reforma del mercado de alquiler podemos esperar la agilización de la movilidad de los inquilinos y la eliminación de las trabas para su desplazamiento, previsiblemente en los tramos y momentos donde pueda producirse una mayor rentabilidad del mercado inmobiliario. Las leyes que articulan esta reforma, la nueva Ley de Arrendamientos Urbanos (Ley 4/2013) y la nueva Ley para las Sociedades de inversión en patrimonio inmobiliario (Ley 121/15), persiguen la flexibilización y agilización de un mercado hasta ahora considerado residual y dominado por los pequeños propietarios. La primera establece plazos más cortos para los contratos de alquiler, al reducir su plazo máximo a la mitad (de ocho años a cuatro con las prórrogas), permite una revisión de las rentas continuas de mutuo acuerdo entre arrendatario e inquilino, agiliza el 'desahucio exprés' en los casos de impago y otorga facilidades para recuperar la vivienda alquilada para su venta o uso por parte de un familiar.
La segunda constituye una vía de inversión para los activos inmobiliarios en el régimen de alquiler (fondos de inversión extranjeros e inversores institucionales) a través de fuertes incentivos fiscales.

2) La rehabilitación, concebida como medida contracíclica, pretende asumir un nuevo dinamismo productivo basado en la intervención sobre la ciudad consolidada y su deteriorado patrimonio edificado, abarcando no tanto el centro como la periferia obrera más antigua. La nueva Ley de rehabilitación, regeneración y renovación urbanas -LRRRUpromueve la generación de nuevos mercados en torno al suelo urbano, encubriendo una posible liberalización del mismo y abriendo la puerta a un nuevo ciclo de especulación sobre la ciudad consolidada. En su consideración los sujetos pasan de ser habitantes o residentes, a representarse exclusivamente por el estatus de la propiedad, en lo que supone una socialización de las responsabilidades sobre la conservación y rehabilitación para pequeños propietarios e inquilinos, y una oportunidad de negocio para grandes empresas con capacidad de invertir. Estas, convertidas en nuevos promotores de la rehabilitación de ciertas áreas, pueden permutar legalmente suelo y trasladar de forma forzosa a los habitantes a otras viviendas. Se contempla que las actuaciones de renovación impliquen la sustitución de edificación, derribos y desalojos y se hace hincapié en la eliminación de la infravivienda, en cuya consideración puede caber una parte amplia del parque más viejo del centro urbano. En este sentido, y a pesar de que el realojo queda contemplado, no se regula con garantías de retorno, lo cual contempla la posibilidad de expulsión de las comunidades residentes vulnerables, ya lo sean por cuestiones socioeconómicas o legales. Aquí tememos que la elaboración de censos de ocupantes legales pueda ser la vía de expulsión de aquellos segmentos de población (la población "no deseada") cuyas formas de convivencia están basadas más fuertemente en redes de apoyo familiar y amistoso (como en el caso de los llamados inmigrantes sin papeles).

El urbanismo de recualificación también aparece como premisa que organiza el marco del futuro Plan General de Madrid (revisión del Plan General de Ordenación 
Urbana de 1997). En el Plan el centro urbano aparece como un elemento que "debe ser intensamente revitalizado, posibilitando el mantenimiento de su función predominantemente residencial y favoreciendo la vuelta de residentes a la ciudad central" (criterio 2: ciudad sostenible- p. 7). Para ello se apela de nuevo a la calidad de vida (criterio 4: ciudad con mayor calidad de vida- p. 8) a través de una batería de elementos que suelen estar presentes en los procesos de gentrificación: nuevos valores culturales a partir del patrimonio, potenciación de los usos culturales de centralidad así como de identidades barriales reconocibles y una continua necesidad de intervenir sobre el espacio público para su mejora a través del diseño urbano; dos dispositivos, el de la esfera pública y la producción cultural señalados como dispositivos de gentrificación en Madrid (Sequera, 2014).

3) La protección de los valores patrimoniales afronta, con la revisión del Catálogo de Edificios Protegidos, una situación de retroceso paradójica, que busca eliminar obstáculos a posibles desarrollos inmobiliarios dentro de áreas centrales, donde tradicionalmente se concentran los elementos de mayor valor histórico. El objetivo de dicha revisión es adecuar el parque edificado a las necesidades de accesibilidad y sostenibilidad económica y ambiental, introduciendo seguridad jurídica para fomentar la recuperación del patrimonio y dinamizar la actividad económica del sector de la rehabilitación (Ayuntamiento de Madrid, 2013).

4) La seguridad, considerada una herramienta destinada a mejorar la convivencia, es una última herramienta para la revitalización de áreas consideradas degradadas (Plan Acción de Lavapiés, 2008) desde dispositivos de normalización y control. El Plan Integral de Mejora de la seguridad y la convivencia de Lavapiés 2012-2015 (promovido por la Delegación de Gobierno de Madrid, diciembre de 2012) contempla que la degradación de la calidad de vida en el barrio de Lavapiés exige una regulación. Según su concepción el barrio tiene un problema: de integración y convivencia, y ambas son reducidas al ámbito de la seguridad; traducida esta exclusivamente al monitoreo permanente, mediante la presencia policial y/o de las cámaras de seguridad.

\section{Principales conclusiones}

En este artículo hemos presentado y explorado las dinámicas que toma la gentrificación en Madrid, sus características y evidencias, en un tránsito temporal desde la década desarrollista (1997-2007) al momento actual de crisis (2008-2014). Para ellos nos hemos apoyado en tres estudios de caso en el centro de Madrid, analizando los cambios en la estructura demográfica principalmente, pero también comercial, e inmobiliaria. El análisis muestra que efectivamente ha habido una profunda transformación urbana en el centro de la ciudad en los últimos quince años, y que los procesos de gentrificación en el centro de Madrid se están consolidando, si bien con ciertas particularidades y ambivalencias.

En relación a las peculiaridades que hemos detectado en cada área de estudio hacemos notar que la antigüedad y la densidad del soporte edificado en Lavapiés, con un patrimonio de vivienda de tamaños claramente inferiores al resto de la ciudad y que recibe unos niveles de inmigración muy superiores a otras áreas, son características intrínsecas de este barrio que pueden actuar como freno y obstáculo a la entrada de dinámicas de transformación urbana más agresivas, pero que sin embargo no impiden que se produzca una renovación y mejora paulatina del tejido residencial y un cambio en las pautas de consumo asociadas al ocio nocturno y a la cultura alternativa. El entorno de la calle Pez nos ha servido como ensayo prematuro para intentar detectar cuáles son los primeros síntomas de transformación asociados al proceso de gentrificación. En casi todas las variables esta área presenta un comportamiento cambiante que va ajustándose cada vez más al perfil estadístico del distrito Centro y de Chueca, señalando una tendencia general a la homogeneización en el espacio central de Madrid, aun albergando procesos con diferentes características. En el caso de esta última, Chueca habría actuado como laboratorio de normalización y aceptación social de la comunidad gay desde finales de los años noventa hasta principios de este siglo, a partir del cual adquiere un perfil cada vez más parecido al conjunto del Centro y se convierte en lugar de recepción residencial de un turismo selecto procedente de Europa 
y Norteamérica. El hecho de que la estructura social y salarial española retrase la capacidad de emancipación económica habría sido una de las claves del éxito de la gentrificación en este barrio, donde se habrían instalado un buen número de profesionales masculinos asociados al mundo de la cultura y el diseño y que rozarían los cuarenta años de edad. La mayor capacidad adquisitiva de este colectivo, debido a que generalmente soportan menos cargas familiares, actuaría como pionero de los cambios en las pautas de consumo del barrio, que se ha ido adaptando a sus propias necesidades proliferando así los negocios relacionados con la moda, el cuidado personal y la oferta gastronómica. Además, aunque no podamos ofrecer las matizaciones oportunas, intuimos que se ha producido una revalorización general de estos espacios a partir del comportamiento inmobiliario, sobre todo en Chueca, donde la contracción de precios es menor y hay un mayor número de intervenciones de rehabilitación. Esta circunstancia nos revela cómo parte de la nueva composición social se habría fijado al territorio.

Este análisis nos permite concluir que existen signos suficientes como para pensar que el fenómeno de la gentrificación ha aterrizado en algunos puntos de la ciudad fruto de la globalización económica de Madrid en los últimos años, y que lo hace desarrollándose en diferentes estadios e interactuando con los procesos previos y peculiaridades de cada ámbito, lo cual no es óbice para intuir una tendencia general en el centro urbano donde empiezan a prevalecer las dinámicas de mercado. Con bastante probabilidad ese proceso se intensificará y se desplazará hacia nuevas fronteras espaciales y sociales como consecuencia de la crisis y de la nueva batería de medidas adoptadas en las políticas urbanas.

Por ello no hemos querido referirnos a la gentrificación como un hecho aislado, sino como un proceso urbano que es al tiempo parte y consecuencia de la reestructuración neoliberal de la ciudad (Theodore et al., 2009). El estudio de caso se acompaña de una reflexión sobre las nuevas tendencias ideológicas en el planeamiento urbano y las políticas públicas, que han desplegado mecanismos, tanto discursivos como jurídicos, que son coadyuvantes a los procesos de gentrificación, y que a día de hoy se apoyan en la regeneración y rehabilitación como un nuevo nicho productivo. En el caso de Madrid consideramos importante señalar cómo la política en materia de urbanismo y vivienda mantiene una actitud aparentemente ingenua ante el curso de estas transformaciones, contemplándolas como un efecto positivo de la recuperación del centro urbano. Las medidas e incentivos adoptados por la política municipal, sean como sean presentadas o justificadas, creemos que van a alimentar y propiciar nuevas dinámicas de gentrificación en otros puntos de la ciudad, sin sopesar los efectos negativos que traen consigo en cuanto a la homogeneización y trivialización urbana, por mencionar alguno. Lejos de frenar, se intenta propulsar y extender aquellas dinámicas que de forma gradual han ido transformando algunos fragmentos de la ciudad, tanto en los usos, como en la población y en la actividad económica.

Esta nueva orientación institucional pasa por encima de consideraciones que valoran los cascos antiguos como espacios sociales singularizados por su heterogeneidad y que, a pesar de haber experimentado transformaciones de diversa naturaleza a lo largo de su historia, son capaces de seguir albergando su propia diversidad interna y el poso de una ciudad vivida. Son signos estos que por el contrario la gentrificación destruye, al introducir elementos y mecanismos tendentes a un paulatino empobrecimiento de la vida urbana y de las relaciones sociales. Puede que gracias precisamente a esta capacidad de resiliencia urbana, espacios apropiados por sectores alternativos o underground de la sociedad logren ofrecer cierta capacidad de resistencia a los procesos de gentrificación. Una pugna entre lugares de representatividad y libertad que aportan nuevas formas de riqueza social y la apropiación constante de ellos por parte de las nuevas economías urbanas. La gentrificación se presenta así como un proceso más perverso y refinado, si cabe, de expropiación urbana, porque con él se complejizan las formas que toma la segregación socioespacial. Con ello no queremos perder de vista que la ciudad es un terreno de acumulación de enorme riqueza, desde lo material a lo simbólico, y que los procesos de gentrificación no son más que una forma más de "acumulación por desposesión" (Harvey, 
2004) que pone en jaque las trayectorias y la vida de muchos residentes en distintos lugares de la ciudad.

\section{Epílogo: nuevas hipótesis en tiempos de crisis}

Con el estallido de la crisis nos encontramos con un Madrid más frágil y dualizado, resultado de la implementación de políticas liberales acompañadas de fuertes dosis de intervención pública, que se han caracterizado por explotar los recursos en los que se ha centrado el núcleo del modelo de acumulación: vivienda, precariedad del empleo, externalización de servicios públicos, sobreexplotación del territorio y privatización de espacios y servicios públicos (Observatorio Metropolitano, 2011). A día de hoy el déficit habitacional para la población joven (sea de clase baja o media) es un enorme escollo. En el contexto actual de ataques al Estado de Bienestar, nos encontramos que esta situación se agrava con la ausencia de instrumentos que garanticen efectivamente el derecho a la vivienda. Además, las familias que lograron incorporarse al mercado inmobiliario están sufriendo ahora de manera dramática el efecto de la crisis en forma de desahucios. A este respecto Fernández y Roch (2012) hacen hincapié en la importancia que tuvo la reforma del espacio social y económico durante la pasada década de cara al impacto de la producción espacial de la ciudad dentro de un discurso y modelo que se proponían como exitosos. Sin embargo, con la quiebra de la ciudad global como hipótesis ganadora para el caso de Madrid, los procesos de estratificación del espacio social de la metrópolis se han acentuado y demostrado tanto más acordes con las reglas de exclusión, tomando la discriminación como nuevo principio dominante.

Para comprender lo anterior, y debido a que los procesos de reproducción del modelo neoliberal urbano actúan en una gran variedad de escalas geográficas, es fundamental analizar las reestructuraciones sociales, políticas, económicas y administrativas mediante estudios que integren y articulen los contextos, los lugares y las escalas en los cuales se originan las políticas urbanas (Brenner et al., 2010). A este respecto, la crisis económica y urbana actual se presenta como un momento particularmente interesante para analizar cómo se producen las adaptaciones y ajustes exigidos por un modelo urbano que requiere de reformulaciones. Los primeros estudios sobre el desigual impacto territorial que está produciendo la crisis (Méndez y Prada, 2014) muestran las asimetrías en la distribución de sus costes y la creciente importancia de las microdesigualdades en el mosaico urbano. En este escenario el centro urbano podría acabar imponiéndose como un espacio exclusivamente para las élites.

Este contexto nos obliga a plantearnos la hipótesis de los procesos de gentrificación en tiempo de crisis en una doble vertiente. Por un lado, como la posible aceleración de los mismos, en la que debido a la bajada de precios del mercado inmobiliario, se encuentren nuevas oportunidades de inversión lucrativa (en la medida que la rehabilitación puede ser el nicho de refugio para la industria de la construcción). Teniendo en cuenta, además, que la crisis está siendo ya una oportunidad para el recrudecimiento de las diferencias de clase, y que los problemas de vivienda no son más que precedentes para una posible gentrificación más viva y fuerte dentro de un tiempo. Tal y como avanzan Díaz Orueta y Lourés (2014) la propia recomposición urbana en torno a la crisis podría crear las condiciones para someter a nuevos territorios de la periferia a procesos de gentrificación, debido a las expectativas que los fondos de capital riesgo han puesto en las inversiones masivas de vivienda en stock ${ }^{12}$.

Por otro lado, la contracción del consumo que se extiende por las capas sociales medias y casi la totalidad de la población joven (ambos actores protagonistas de los procesos de gentrificación) nos hace suponer paralelamente un posible estancamiento y retroceso de las dinámicas de revalorización urbana; es decir, en el escenario de caída de precios, no se dan las condiciones de rentabilidad que la gentrificación requiere, lo cual puede

\footnotetext{
12 "La Comunidad vende 3.000 pisos de protección del Ivima por 201 millones" [en línea]. El País digital, 9 agosto 2013. Disponible en Internet: http://ccaa.elpais.com/ccaa/2013/08/09/madrid/1376060709_940816.html
} 
que nos obligue a replantear alguna de las dimensiones de la gentrificación en función de la forma que adquiera el proceso a partir de ahora. Cabría esperar aquí una ralentización de dicho proceso, que en cualquier caso no es una garantía de equilibrio social.

En esta oscilación hay que contemplar que los procesos de transformación urbana neoliberal en Madrid han sido más tardíos que en otros contextos y ciudades (sobre todo las anglosajonas), y con otras condiciones de partida: tanto institucionales, discursivas, de mercados inmobiliarios y parque de vivienda de protección social, como de relaciones de clase y raza y resistencia a los procesos. Si tomamos como ejemplo las crisis que sufrieron dichos países en los años noventa sabemos que estas crisis precedieron a una ola más agresiva de gentrificación posterior (casos de Nueva York y Londres, por ejemplo). En este nuevo escenario más bien contemplamos la posibilidad de dos fenómenos simultáneos: de gentrificación a gran escala, en el marco de un proyecto de segregación de clases urbanas donde el centro queda para las élites, versus la gentrificación instantánea (provocada por operadores comerciales, como Triball por ejemplo), que produce pequeñas manchas en un espacio heterogéneo y complejo como es el centro urbano. Es necesario atender aquí a las variadas geografías de la gentrificación y a sus contextos locales (Butler \& Lees; 2006) en la medida que estos van a adaptarse creativamente al momento de reestructuración neoliberal postcrisis financiera mundial.

Sea como fuere, y a pesar de que la hegemonía del neoliberalismo urbano parezca incontestable, este no es un proceso lineal y no está exento de contradicciones (Theodore et al., 2009). Las contestaciones de los movimientos sociales a los efectos de las crisis, a pesar de la crudeza impuesta por la austeridad, permite imaginar alternativas esperanzadoras que discurren por esas grietas. En primer lugar porque este periodo ha creado, según Stavrides (2013) un nuevo modo de producir sujetos políticos. Que no son simplemente sujetos de acción y reclamo, sino de proposición y creación. Las experiencias reivindicativas vividas en Europa (incluido Madrid, con el movimiento 15M) están muy ligadas al reclamo de un nuevo tipo de demo- cracia; y en ellas surgen nuevas formas de colaboración y producción basadas en el "hacer (en) común". Estas prácticas son, además de una forma de reclamar nuestras propias vidas, un medio para proponer una manera distinta de componer la vida social.

La gentrificación, como mecanismo de extracción de plusvalías urbanas, pone de manifiesto, a nuestro juicio, la pugna por el espacio urbano y la negociación de la identidad. Pero los espacios de oportunidad lo son tanto para el capital como para las prácticas antagonistas. Existe posibilidad alternativa donde hay vacíos que Ilenar, tanto a nivel físico como de construcción simbólica, la cuestión es poner en evidencia qué segmentos de la población se benefician de la apropiación de la plusvalía urbana, y cómo esta es repartida, habiendo contribuido a su valor todo el conjunto de la ciudad y sus habitantes. En este sentido, quizás la mejor forma de resistir sea quizás la que Stavrides señala, la que permite mantener y proteger una forma de acumulación y la riqueza social de forma comunitaria sin la destrucción de los lazos sociales. A pesar de la creciente privatización de todos los ámbitos de la vida, la ciudad no puede ser devorada completamente porque es, por esencia, común (sobre el concepto de commons puede consultarse Ostrom, 2000). El derecho a la ciudad se convierte por tanto en la garantía de acceso y gestión a los comunes urbanos, en el poder colectivo y la libertad individual para ejercer la transformación de la ciudad. Se presenta este como el momento crítico para la reinvención del vínculo social, la gran oportunidad para reactualizar ese viejo "derecho a la ciudad" formulado en los años setenta por Henri Lefebvre y que pasa por considerar a las ciudades y al entorno urbano como un enorme territorio de riqueza social y material, común a todos los que la hacen posible. Una verdadera hipótesis de ciudad postcapitalista (Harvey, 2013).

\section{Referencias bibliográficas}

ALPUENTE, M. 'Gentrificación'. El país digital, 4 de junio de 2008. Disponible en Internet: http://www.elpais.com/articulo/madrid/Gentrificacion/ elpepuespmad/20080604elpmad_9/Tes 
BIDOU-ZACHARIASEN, C. (director). Retours en ville. Paris: Descartes \& Cie, 2003.

BORJA, J. Luces y sombras del urbanismo de Barcelona. Barcelona: Editorial UOC, 2009

BRENNER, N.; PECK, J., \& THEODORE, N. Variegated neoliberalization: geographies, modlities, pathways. Global Networks, 2010, Vol. 10, No 2, p. 182-222.

BURRIEL, E. La "década prodigiosa" del urbanismo español (1997-2006). Scripta Nova. Revista Electrónica de Geografía y Ciencias Sociales, 2008, Vol. XII, No 270 (64). Disponible en Internet: http://www.ub.es/ geocrit/sn/sn-270/sn-270/sn-270-64.htm

BUTLER, T. \& LEES, L. Super-gentrification in Barnsbury, London: globalization and gentrifying global elites at the neighbourhood level. Transactions of the Institute of British Geographers, 2006, Vol. 31, No 4, p. 467-487.

CALVO, R.; GARCÍA, E.; MOLINA, P.; RIEZNIK, N. y SÁNCHEZ, A. La explosión urbana de la conurbación madrileña. En: OBSERVATORIO METROPOLITANO. Madrid: ¿la suma de todos? Globalización, territorio, desigualdad. Madrid: Traficantes de Sueños, 2007, p. 223-325.

CERRILLO I MARTÍNEZ, A. La Gobernanza hoy: 10 textos de referencia. Madrid: Instituto Nacional de Administración Pública, 2005.

DELGADO, M. La ciudad mentirosa: fraude y miseria del 'modelo Barcelona'. Madrid: Ediciones La Catarata, 2007.

DE SANTIAGO RODRÍGUEZ, E. Madrid, 'ciudad única'. Pautas y lógicas espaciales recientes en la región madrileña: las grandes transformaciones estructurales; el despliegue del nuevo 'paradigma único' en la región urbana de Madrid. Urban, 2007, No 12, p. 8-33.

DÍAZ ORUETA, F. y LOURÉS, ML. EI análisis de la gentrificación y la crisis en la ciudad neoliberal. En: Working paper series Contested_Cities, WPCC-1400, mayo 2014. Disponible en Internet: http://contested-cities. net/working-papers/2014/gentrificacion-y-lacrisis-en-la-ciudad-neoliberal/

DÍAZ PARRA, I. Procesos de gentrificación en Sevilla en la coyuntura reciente. Análisis comparado de tres sectores históricos: San Luis-Alameda, Triana y San Bernardo (2000-2006). Scripta Nova. Revista Electrónica de Geografía y Ciencias Sociales, 2009, Vol. XIII, No 304. Disponible en Internet: http://www.ub.edu/geocrit/sn/sn-304.htm

DOMÍNGUEZ, M. y VILA, G. Los centros urbanos de las grandes ciudades españolas: una perspectiva demográfica y urbanística. Los casos de Madrid y Barcelona. En: Ponencia en XI Congreso Español de Sociología. Crisis y Cambio, propuestas desde la sociología. Madrid, 10-12 julio 2013.

DONZELOT, J. La ville à trois vitesses: relégation, périurbanisation, gentrification. Esprit, 2004. Disponible en Internet: http://www.esprit.presse.fr/review/article. php? code $=7903$

DUQUE, R. Procesos de gentrificación de cascos antiguos de España: El Albaicín de Granada. Granada: Tesis doctoral, Universidad de Granada, 2010. Disponible en Internet: http://digibug.ugr.es/ bitstream/10481/15460/1/19657602.pdf ]

FANJUL, S. "Pobre barrio rico". El país digital, 31 de marzo de 2013. Disponible en Internet: http://ccaa.elpais.com/c c a a / $2013 / 03 / 30 / \mathrm{ma}$ drid/1364665402_303415.html

FERNÁNDEZ, C. y ROCH, F. La quiebra de la ciudad global y sus efectos en la morfología urbana. Madrid, bajo la lógica inmobiliaria de la acumulación-desposesión. Urban, 2012, No n503, p. 45-63.

FLORIDA, R. Las ciudades creativas. Por que donde vives puede ser la decisión más importante de tu vida. Barcelona: Paidós, 2009.

GARCÍA PÉREZ, E. El regreso a la ciudad. Revista Ciudades, 2012, No 95, p. 18-24.

GARCÍA PÉREZ, E. y MOLINA COSTA, P. De la gestión urbana al empresarialismo 
en la ciudad de Madrid, Boletín CF+S, 2010, $N^{\circ}$ 44. Disponible en Internet: http://habitat. aq.upm.es/boletin/n44/aegar.html

GARCÍA, E.; MOLINA, P. y RODRÍGUEZ, E. Madrid. Explosión y crisis del modelo urbano en Ciudades y Caos Sistémico. En: SMITH, N. (coordinador). Contratextos. Barcelona: Macba-Uab, 2009, p. 31-42.

GENTRISAÑA, Gentrificación en Malasaña, 2013. Disponible en Internet: http://gentrisania.wordpress.com/

GENTRIPIES, Gentrificación y lucha social en Lavapiés. 2013. Disponible en Internet: http://lavapiesingentrificable.wordpress.com

GÓMEZ, M. \& GONZÁLEZ, S. A reply to Beatriz Plaza's 'The Guggenheim-Bilbao Museum Effect'. International Journal of Urban and Regional Research, 2001, Vol. 25, No 4, p. 898-900.

HARVEY, D. El 'nuevo' imperialismo: acumulación por desposesión. Socialist register, 2004, No 42, p. 99-129.

HARVEY, D. Espacios del Capital. Hacia una geografía crítica. Madrid: Akal, Cuestiones de antagonismo, 2007.

HARVEY, D. The importance of postcapitalist imagination. From housing to wages. Interview, 2013. Dipsonible en Internet: http:// www.redpepper.org.uk

JANOSCHKA, M.; SEQUERA, J. y SALINAS, L. Gentrification in Spain and Latin America- a critical dialogue. International Journal of Urban and Regional Research, 2013, No37, p. 1234-1265.

JANOSCHKA, M. y SEQUERA, J. Gentrification dispositifs in the historic centre of Madrid: A re-consideration of urban governmentality and state-led reconfiguration. In: LEES, L.; SHIN, H.-B. \& LÓPEZ, E. (editors). Global gentrifications. Uneven development and displacement. London: Policy Press, 2005.

LEAL MALDONADO, J. y DOMÍNGUEZ PÉREZ, M. Transformaciones económicas y segregación social en Madrid. Ciudad y Terri- torio. Estudios Territoriales, 2008, № 158, p. 703-725.

LEAL, J. y MARTÍNEZ, A. La segregación residencial, un indicador espacial confuso en la representación de la problemática residencial de los inmigrantes económicos: el caso de la Comunidad de Madrid. ACE: architecture, city and environment, 2008, No 8, p. 53-64.

LEAL, J.; MARTÍNEZ, M.; ECHAVES A., y GARCÍA, E. Densidades urbanas y sociales en dos barrios centrales de Madrid: virtudes, excesos y desigualdades de fondo. Urban, 2012, No n504, p. 61-79.

LÓPEZ, I. y RODRÍGUEZ, E. Fin de ciclo. Financiarización, territorio y sociedad de propietarios en la onda larga del capitalismo hispano. Madrid: Observatorio Metropolitano, Traficantes de Sueños, 2010.

MÉNDEZ, R. y PRADA-TRIGO, J. Crisis, desempleo y vulnerabilidad en Madrid. Scripta Nova. Revista Electrónica de Geografía y Ciencias Sociales, 2014, Vol. XVIII, No 474. Disponible en Internet: http://www.ub.edu/ geocrit/sn/sn-474.htm

MONCLÚS, F.J. The Barcelona model: and an original formula? From 'reconstruction' to strategic urban projects (1979-2004). Planning Perspectives, 2003, Vol. 18, № 4, p. 399-421.

MUÑOZ, O. El proceso de gentrificación en el municipio de Madrid (1996-2001). En: GALLEGO, S. y GÓMEZ, M. (editores). Igualdad, desarrollo y cooperación: 13, 14 y 15 de noviembre de 2009. Ciudad Real: Palacio de los Condes de Valdeparaíso, Almagro. Asociación Castellano-Mandrega de Sociología, 2009, p. 317-332.

OBSERVATORIO METROPOLITANO. Manifiesto por Madrid. Crítica y crisis del modelo metropolitano. Madrid: Traficantes de Sueños, 2009.

OBSERVATORIO METROPOLITANO. La Crisis que viene. Algunas notas para afrontar esta década. Madrid: Traficantes de Sueños, 2011. 
OBSERVATORIO METROPOLITANO. Jornadas sobre Gentrificación: La lucha de clases en la ciudad. Madrid: observatoriometropolitano.org, 2013.

OSTROM, E. El Gobierno de los Bienes Comunes: La Evolución de las Instituciones de Acción colectiva. México: Universidad Nacional Autónoma de México, 2000.

PECK, J. \& TICKNELL, A. Neoliberalizing Space. Antipode, 2002, Vol. 34, p. 380-404.

RODRÍGUEZ LÓPEZ, E. La ciudad global o la nueva centralidad de Madrid. En: Madrid ¿la suma de todos?, globalización, territorio, desigualdad. Madrid: Observatorio Metropolitano, Traficantes de Sueños, 2007, p. 41-93.

SARGATAL BATALLER, MA. ALBA. El estudio de la gentrificación. Biblio 3W, Revista bibliográfica de geografía y ciencias sociales, 2000, No 228. Disponible en Internet: http:// www.ub.es/geocrit/b3w-228.htm

SEQUERA, J. Gentrificación en el centro histórico de Madrid: el caso de Lavapiés. En:
HIDALGO, R. y JANOSCHKA, M (editores). La ciudad neoliberal. Santiago de Chile: Serie GEOlibros, Instituto de Geografía, Pontificia Universidad Católica de Chile, 2014, p. 233 255.

STAVRIDES, S. Después de Sintagma. Eva García y Beatriz García, entrevista a Stavros Stavrides. Diagonal Periódico, 2013. Disponible en Internet: https://www.diagonalperiodico.net/culturas/stavrides.html

THEODORE, N.; PECK, J. y BRENNER, N. Urbanismo neoliberal: la ciudad y el imperio de los mercados. Temas Sociales, 2009, $\mathrm{N}^{\circ}$ 66, p. 1-12.

TROITIÑO VINUESA, MA. Centro histórico, intervención urbanística y análisis urbano. Anales de geografía de la Universidad Complutense, 1992, No 11, p. 25-48.

UNIÓ TEMPORAL D'ESCRIBES (UTE). Barcelona, marca registrada. Un model per desarmar. Bilbao: Virus editorial, 2004. 
